\title{
Caminhos descoloniais possíveis no ensino de Ciências das séries iniciais: um diálogo com a obra Meu crespo é de rainha
}

lago Vilaça de Carvalho iago.v.carvaho@gmail.com $\frac{\text { orcid.org/0000-0002-4415-4226 }}{\text { Universidade Federal do Rio de Janeiro }}$ (UFRJ), Macaé, RJ, Brasil.

Brenda lolanda Silva do Nascimento

brendaiolandab@gmail.com

orcid.org/0000-0002-3493-881X

Universidade Federal do Rio de Janeiro (UFRJ), Macaé, RJ, Brasil.

Stella Almeida

stella.swc@hotmail.com

orcid.org/0000-0002-6973-602X Universidade Federal do Rio de Janeiro (UFRJ), Macaé, RJ, Brasil.

Fernanda Antunes Gomes da Costa

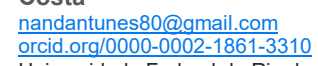
Universidade Federal do Rio de Janeiro (UFRJ), Macaé, RJ, Brasil.

\begin{abstract}
RESUMO
Nosso estudo tem por objetivo pensar a aula de Ciências para as séries iniciais do Ensino Fundamental a partir da perspectiva orientada pela Lei 10.639/03, em que aspectos da História e da Cultura Africana e Afro-brasileira devem ser abordados em todo currículo escolar. Para tal, trazemos à tona o tecer teórico de Silvia Cusicanqui, Grada Kilomba e Bell Hooks, autoras que problematizam a descolonização dos saberes, ou seja, propõem uma possibilidade de produção do conhecimento a partir de epistemologias silenciadas, da subjetividade e da prática docente. Diante do que nos ensinam essas pensadoras, buscamos, portanto, desenvolver uma reflexão teórica acerca do diálogo entre a Lei 10.639/03, o ensino de Ciências e a literatura. Para tal, o livro infantil escolhido para nossa abordagem é a obra Meu crespo é de rainha, da autora e intelectual negra Bell Hooks, visando o alinhamento entre nossa construção teórica, a literatura infantil e a disciplina de Ciências para as séries iniciais do Ensino Fundamental. Como resultado, sugerimos caminhos para efetivação da Lei 10.639/03 em uma perspectiva descolonial, tornando, assim, a educação das relações étnico-raciais possível também ao campo científico, que pode e deve contribuir com essa discussão. Acreditamos, portanto, que subverter a lógica de uma história única pautada em uma produção científica predominantemente hegemônica é poder construir percursos para uma nova Ciência.
\end{abstract}

PALAVRAS-CHAVE: Ensino de Ciências. Descolonização. Literatura. 


\section{INTRODUÇÃO}

Quando pensamos em infância, certamente recordamos de dias distantes que outrora nos marcaram de diversas maneiras. Tais lembranças são regadas de experiências únicas que dizem respeito às nossas impressões iniciais sobre as particularidades da realidade que nos cerca. Sem dúvida, essas impressões, além de serem arrebatadores lampejos saudosistas, caracterizam-se por traçar os primeiros passos para a construção de nossa identidade no mundo.

Paulo Freire, em A Importância do Ato de Ler (2006), fala-nos com satisfação sobre suas recordações acerca dos primeiros contatos com a realidade ao seu redor: possibilidades de sons, cores e percepções que lhe renderam, além de boas memórias, o contato com os sentidos e com os elementos físicos e biológicos da natureza, todos registrados em sua narrativa nostálgica. Tudo isso se traduziu em sua "palavramundo" (FREIRE, 2006, p.15), termo que expressa a concepção de interpretação da realidade a partir da leitura do mundo.

Freire (2006) ainda nos conta que houve um sujeito de grande importância para o desenvolvimento do seu processo de leitura. O autor narra que sua professora, Eunice Vasconcelos, deu seguimento à alfabetização iniciada em casa com os próprios pais, ensinando a Freire os componentes da linguagem que, para além da possibilidade de acessar a língua por meio das palavras, permitiu-Ihe acessar a língua pela palavramundo.

Partindo desta narrativa, encontramos a provocação necessária para assumir uma postura crítica sobre o papel dos professores em uma educação preocupada com a curiosidade. Vale lembrar que esta reflexão não ignora a atividade docente em prol de uma prática desfocada e despreocupada com o rigor ou com o método. Afinal, como diz Freire, a "prática educativo-crítica é o que me adverte da necessária promoção da curiosidade espontânea para curiosidade epistemológica" (2013, p. 86). É possível, assim, considerar tanto a aprendizagem do aluno quanto a experiência pedagógica do professor como práticas libertadoras. A partir do exposto, encontramos subsídios para mostrar, ao longo deste texto, a importância de se pensar novas abordagens educacionais na infância e no processo de formação dos alunos.

Nesse contexto, enxergamos o tecido educacional que o ensino de Ciências se configura como uma pedra angular do despertar para o ímpeto da curiosidade, sendo também um precursor para a investigação, já que a aprendizagem de ciências impulsiona a dúvida e o questionamento, potencialmente levando à descoberta. Estas coisas, quando fomentadas em uma criança, impulsionam novas possibilidades de interação, de ver e estar com/no mundo. Sendo assim, as professoras e os professores de Ciências têm o papel de orientação no estabelecimento de bases do pensamento científico que tratam de 
Para a autora, utilizar esta predisposição dos alunos pelo anseio de conhecer o mundo é permitir que os discentes construam uma sociedade engajada e que disponham de mecanismos próprios de administrar o próprio pensamento. Quando isto não acontece, um cenário arriscado em que a curiosidade dos estudantes é suprimida pode surgir, perdendo-se a capacidade de expressá-la (FURMAN, 2009).

Tomando esta necessidade de concretização de uma educação engajada, recorrendo novamente às ideias de Freire (2006), apontamos para a importância da atuação docente na implementação de outro olhar didático, direcionando a prática pedagógica para uma prática mais humanizada, voltada para a cidadania, principalmente na infância e nas séries iniciais, a fim de estimular o potencial criativo dos alunos para que estes possam desenvolver outras leituras de mundo possíveis. Assim, em diálogo com a autora Bell Hooks (2013), podemos pensar em novos contextos para a sala de aula, por meio da reafirmação dos sujeitos presentes nas comunidades de aprendizagem enquanto protagonistas na construção do conhecimento crítico. Sobre isso, estamos convencidos de que um caminho para esta formação crítica do pensamento científico precisa contar com um viés epistemológico que prime pela descolonização dos saberes nas Ciências e da própria subjetividade dos atores envolvidos, estabelecendo em seu exercício, sobretudo, o comprometimento com as pautas raciais, de gênero e classe.

Com base nas discussões de autores e principalmente de autoras, negras e do Sul Global, podemos vislumbrar as contribuições importantes para o ensino de Ciências a partir da formulação de uma nova linguagem científica descolonizada que só se torna possível na transgressão dos limites pré-estabelecidos entre as diversas áreas do conhecimento. Diante deste quadro, o campo da Literatura se apresenta não só como horizonte possível de diálogo fronteiriço, mas também como ferramenta de ressignificação da nossa relação com nós mesmos, com o mundo que nos cerca e com os saberes adquiridos ao longo da vida.

Dessa forma, ao trabalharmos as Ciências a partir da literatura, acreditamos que seja possível nos reconhecer como parte fundamental da construção do pensamento científico, assumindo a diversidade e a pluralidade de narrativas presentes nesse processo, em contramão à história única proferida pelo colonizador em pacto com o cientificismo positivista e universal.

Segundo estes preceitos, este artigo seguirá com a seguinte tecitura: inicialmente, apresentaremos a discussão sobre a descolonização do ensino de Ciências, pautando-nos em teóricas como Bell Hooks (2013), Grada Kilomba (2019), Silvia Cusicanqui (2010, 2015); na sequência, apresentamos uma possibilidade de confluência entre a descolonização de saberes e a Lei 10.639/03; em seguida, como etapa metodológica, realizamos a apresentação do livro infantil Meu crespo é de rainha (2018), da autora e intelectual negra Bell Hooks, visando o alinhamento entre nossa construção teórica e a literatura infantil. Por fim, como encaminhamento final, apontamos para as conclusões provisórias que este estudo alcança. 


\section{PENSANDO A DESCOLONIZAÇÃO NO ENSINO DE CIÊNCIAS: POR UMA OUTRA EDUCAÇÃO}

É comum que a primeira menção ao continente africano, ou aos povos africanos, na escola seja através dos navios tumbeiros, ou como são conhecidos, negreiros, durante o período escravagista. A partir deste primeiro contato com o corpo negro, historicamente violentado, cria-se uma dimensão ontológica da condição da escravidão. De acordo com Bárbara Carine Pinheiro, isto

é um traço fundamental constitutivo da nossa identidade ancestral. Aprendemos que viemos de 'escravos'. Obviamente que alguém que vem de 'escravos' não se sente privilegiado em sua origem e constrói uma relação psíquica causal e direta que justifica seu atual rebaixamento social, sua não detenção de bens materiais e imateriais é justificada pela relação com sua origem (PINHEIRO, 2019, p. 331)

Dessa forma, ao perceber a individualidade negra marcada pelos laços coloniais, um(a) estudante, por exemplo, introjeta uma narrativa histórica que atribui ao corpo negro uma condição de existência essencialmente subalternizada. Esta violência simbólica pode ser percebida, além da dimensão física, através do apagamento do legado histórico e cultural da África que, por milênios, edificou impérios, conhecimentos, epistemologias e cosmovisões, tudo isso excluído do horizonte da possibilidade (PINHEIRO, 2019). Assim sendo, não enxergamos como opção a persistência da (i)moralidade que fundamenta o discurso da modernidade, muito menos um caminho educacional que não seja direcionado pela descolonização dos conhecimentos científicos e escolares.

Acerca dos conhecimentos científicos, Grada Kilomba nos leva a refletir, em Memórias da Plantação (2019), sobre a maneira como os conhecimentos são produzidos, além da sua relação com o mito da objetividade e da neutralidade, afirmando que as estruturas que validam o conhecimento são controladas sob a lógica eurocêntrica/branca que, por sua vez, institui perspectivas ditas universais e que não privilegia pessoas de cor. A partir disso, a ideia daquilo que chamamos de conhecimento científico fica condicionado como propriedade da branquitude, resultando não numa verdade objetiva e neutra, mas sim, em relações de poder assimétricas de cunho racial entre os grupos. Sendo assim, a autora nos chama a atenção sobre o fato de que pessoas negras ao vivenciarem o racismo, vão avaliar a realidade de maneira diferente das pessoas brancas. Portanto, os temas considerados científicos, assim como suas metodologias e paradigmas, utilizados para a explicação de suas ditas verdades, podem não ser coerentes com a realidade e as experiências de vida das pessoas negras, portanto, condicionando-as na margem das relações sociais. Ainda, a respeito do processo de marginalização de pessoas negras, inclusive no campo da construção da intelectualidade, a autora, em diálogo com Bell Hooks, salienta que apesar da margem ser considerada um espaço de privação e perda também é um espaço de criatividade e possibilidades, pois a partir da margem é possível construir críticas dialogando com categorias como raça, gênero, sexualidade e classe. (KILOMBA, 2019).

Logo, pensar no ensino de Ciências que reconheça as margens, construídas historicamente, e que conceba políticas de escuta de pessoas subalternizadas, pode contribuir para o desenvolvimento de novas possibilidades no processo formativo das habilidades e competências de cada indivíduo. Nesse sentido, 
visando os conhecimentos escolares, Hooks (2013) versa a respeito de uma educação que se propõe transgressora, palavra que aqui assume o sentido de resistência às injustiças sociais e de comprometimento com a prática da liberdade. Muito inspirada por Paulo Freire, a autora aponta para a necessidade de traduzir na educação um desejo de transgredir as fronteiras que perpetuam condições opressivas de gênero, classe e raça através de uma prática de fato libertadora. Quando pensada no contexto da sala de aula, a educação que não dialoga com uma pedagogia radical - aquela que subverte a desigualdade nos padrões de poder presentes na educação- só distancia os educandos do pensamento crítico, contribuindo para uma aprendizagem que nutre uma estrutura de pensamento estático, desvencilhado da realidade e colonizada (HOOKS, 2013). Portanto, tornase imperativo pensar em estratégias que visam à descolonização dos conhecimentos das aulas de Ciências a partir de propostas transgressoras e comprometidas com a justiça social.

A partir dessa discussão, ao pensar em países que foram colonizados por europeus, autoras como a boliviana Silvia Cusicanqui - socióloga, professora e ativista - nos chama atenção para a necessidade de descolonização da nossa subjetividade e dos saberes produzidos na sociedade. Diante desse processo, a autora discute e propõe a descolonização a partir de imagens produzidas pela vivência dos povos que foram colonizados (CUSICANQUI, 2010). A partir desse posicionamento político, metodológico e epistêmico, a autora coloca em evidência que não há discurso descolonizado que não seja fruto de uma prática cotidiana de descolonização. Além disso, inicia uma teoria crítica para entender a situação colonial a partir das representações indígenas que divergem da história oficial da Bolívia. Esta teoria, que foge à historiografia clássica, a autora denomina Sociología de la imagen (CUSICANQUI, 2010; CUSICANQUI, 2015).

Para Cusicanqui (2010, p. 13, tradução nossa), “É evidente que em uma situação colonial, o 'não dito' é o que mais significa; as palavras escondem mais do que revelam, e a linguagem simbólica entra em cena [...]". Para a autora, isto é percebido ao analisar a historiografia do movimento katarista, movimento do campesinato boliviano nomeado em homenagem a Tupaq Katari, líder revolucionário aymara do século XVIII. Segundo Silvia, os movimentos liderados por Tupaq Katari foram estigmatizados e banalizados como estritamente radicais e violentos. Para alguns, a condenação do líder foi um ato de bravura e valentia das autoridades coloniais espanholas da época. No entanto, na obra de Waman Puma, escritor andino de ascendência inca, a condenação do líder revolucionário assume uma representação de violência simbólica ao povo aymara, visto que as imagens de seu livro são propositalmente alteradas em relação à narrativa histórica a fim de expressar o insulto acometido àquela população pela perda de seu líder.

Outro exemplo citado por Cusicanqui (2010) se dá em outra ilustração, em que uma autoridade colonial senta à mesa em banquete com outras autoridades, inclusive indígenas, enquanto um pequeno índio recolhe as sobras de comida no chão. Na análise de Silvia, o que estava representado não é uma criança, e sim, um indígena adulto. $\mathrm{O}$ fato de Waman Puma tê-lo representado em tamanho infantil se deveu ao fato da condição do indivíduo representado caracterizar uma real diminuição do sujeito, já que nas línguas aymara y qhichwa a palavra que mais se 
aproxima da ideia de exploração ou opressão tem o significado de diminuição ou humilhação do sujeito, associada à servidão.

Assim, nas palavras de Cusicanqui (2010, p. 20, tradução nossa): “As imagens nos oferecem interpretações e narrativas sociais que desde os séculos précoloniais iluminam esse contexto social e oferecem perspectivas de compreensão crítica da realidade". Nesta perspectiva, a análise de Silvia se faz extremamente lúcida e inédita, pois, traz à tona os sentidos estabelecidos pelo processo de colonização segundo a perspectiva dos vencidos e silenciados historicamente.

Propondo um outro caminho para a prática de descolonização de saberes hegemônicos, enxergamos, neste artigo, que o campo das representações imagéticas dentro do ensino de Ciências pode apresentar uma forma de se pensar em novas linguagens. Isso porque compreendemos que a linguagem é também uma das heranças coloniais e, por isso, voltamos nossa atenção para as imagens, local de interpretação e construção de sentidos que oferece uma possibilidade de ruptura da reafirmação do processo de colonização, através das representações que partem da fronteira da opressão e dos limites construídos para os povos marginalizados.

Para este artigo, isso se mostrará possível já partir das séries inicias do Ensino Fundamental, principalmente quando recorremos a outra forma de apresentação do mundo em suas imagens e linguagens: a literatura. Literatura que pode, em seu enredo, palavras e cenários, possibilitar a descolonização dos saberes, a discussão proposta pela Lei 10.639/03 e, portanto, a Educação das Relações Étnico-Raciais no ensino de Ciências.

\section{LEI 10.639/03: PERCURSOS DESCOLONIAIS POSSÍVEIS}

A Lei 10.639/03 tornou obrigatório o ensino da História e da Cultura afrobrasileira e africana em todas as instituições de ensino do Brasil (BRASIL, 2003), modificando a Lei de Diretrizes e Bases da Educação Nacional (LDBN) - 9.394/96 em prol dos direitos sociais e da cidadania. No entanto, muitas dificuldades ainda circundam a implementação dessa orientação, levando, para o espaço escolar, questionamentos sobre "como construir caminhos para tais discussões?"; "quais disciplinas podem dialogar com a Educação das Relações Étnico-Raciais?"; "como trabalhar com a lei nas séries iniciais do Ensino Fundamental?"; entre outras questões que podem surgir. Assim, propostas e estratégias que promovem tais reflexões são de suma importância ainda hoje, mesmo após 16 anos de promulgação da referida lei.

A historiadora e professora Verena Alberti $(2013$, p.27) ressalta que a Lei 10.639/03 é um instrumento importante para o combate ao racismo no Brasil, por ser uma ferramenta de conscientização. Ela destaca ainda que por ser o racismo um problema de todos, já que envolve toda a sociedade, o educador, profissional responsável pela mudança social, também deve se inserir nessa questão, assumindo sua responsabilidade na viabilização dessa discussão. Para isso, caminhos devem ser traçados e atividades devem ser pensadas como ferramentas que tornarão a efetivação da lei significativa, tomando como foco um currículo escolar preocupado e engajado aos aspectos que envolvem a diversidade cultural, racial e social do nosso país. Para além, ousamos afirmar que a Lei $10.639 / 03$ pode 
ser um percurso para descolonização do currículo, portanto, para descolonização dos saberes.

Cabe ressaltar que nossa LDBN já versava acerca de um ensino que devesse respeitar ideias plurais e princípios de igualdade (BRASIL, 1996), mas, de fato, a Lei 10.639/03 veio para promover uma reflexão enfática na prática docente e na possiblidade da efetivação plena das orientações feitas pelas Diretrizes Nacionais Curriculares para Educação das Relações Étnico-Raciais (2004). Ou seja, as orientações da lei acabam por mostrar de que forma as escolas podem e devem incentivar outros conhecimentos, para além daqueles reconhecidos hegemonicamente. Isso sem dúvida envolve uma discussão cara, principalmente em países como o Brasil, sobre o processo de colonização que está longe do fim, quando, por exemplo, percebemos isso perpetuado no currículo escolar. Basta nos questionarmos sobre o seguinte: por que, mesmo a lei afirmando que o ensino da História e da Cultura Afro-brasileira deve ser ministrado em todo âmbito do currículo, algumas disciplinas se colocam distantes dessa orientação? O que tem sido feito para que professores, também formados por um currículo genuinamente ocidental, tenham a capacitação necessária para trabalhar com a Educação das Relações Étnico-Raciais na escola?

No geral, vemos as matérias de Humanidades assumindo o papel de disciplinas que promovem a efetivação da lei, como se o continente africano não pudesse ter contribuições a fazer nas Ciências e na Matemática. Será apenas o continente africano uma história a ser contada, sem condições de protagonizar o enredo de uma descoberta científica ou contribuição na produção de conhecimento para humanidade? No mínimo, isso sugere que, antes da Lei 10.639/03, a nossa LDBN já enfrentava dificuldades para promover verdadeiramente a pluralidade em nossos currículos. Com a Lei essa descolonização se mostra de forma mais abrangente não porque conseguiu superar as dificuldades de sua implementação, mas justamente por ela nomear quais povos e culturas da nossa origem social ficaram de fora daquilo que se entendia por pluralidade epistemológica: povos negros e, um pouco mais a frente com a Lei 11.645/08, povos indígenas (BRASIL, 2008).

Bárbara Carine Soares Pinheiro e Katemari Rosa, organizadoras da obra Descolonizando saberes (2018), livro fundamental na discussão da Lei 10.639/03 para o ensino de Ciências, reforçam que não "se trata apenas de reparação, tratase de trazer à tona realidade de fatos, uma realidade triste de genocídio, epistemicídio e pilhagem cultural e epistêmica" (2018, p. 16). Trata-se de admitirmos que grandiosos conhecimentos foram silenciados para que a colonização se perpetuasse também através da escolarização das nossas crianças, permitindo não apenas que histórias únicas fossem repetidas como sendo possibilidades exclusivas de contar o mundo, assim como consentindo que identidades fossem afetadas e desrespeitadas em nome de um projeto de poder. Portanto, só há como pensar uma outra ciência se pensarmos em outras possibilidades de falarmos sobre conhecimento e suas origens.

Retomamos Grada Kilomba no que diz respeito ao conhecimento e o mito do universal. Como já observado, a autora põe em questão a maneira como o conhecimento é produzido e validado, já que a lógica predominante nesse processo de validação, daquilo que será concebido como verdade, é, na maioria das vezes, tecida a partir de uma perspectiva eurocentrada e branca. Isso significa 
dizer que muitos povos, principalmente no que diz respeito à população negra e saberes, estão à margem da construção epistemológica. $\mathrm{O}$ que está sendo validado, então, não tem nenhuma relação, portanto, com neutralidade ou com universalidade. Envolve, por assim dizer, uma relação de poder muito bem exposta nesse território em disputa que é o do conhecimento. Grada Kilomba, pergunta de forma reflexiva: "Qual conhecimento está sendo reconhecido como tal? E qual conhecimento não é? Qual conhecimento tem feito parte das agendas acadêmicas? (...) E quem permanece fora, nas margens?" (KILOMBA, 2019, p. 50).

É sobre essa margem que a Lei 10.639/03 tem se dedicado a discutir. No momento em que as instituições de ensino se encontram incentivadas a buscar epistemologias silenciadas, a partir da orientação da lei, temos a oportunidade de formar nossos alunos em uma perspectiva do (re)conhecimento, oportunizando outras vozes, evitando a história única que deixa à margem fatos científicos que fazem parte da história da humanidade. Isso não deve ser pensado apenas em disciplinas isoladas ou em momento oportuno, como a preparação para vestibulares. Pelo contrário. O que a orientação das Diretrizes Nacionais para Educação das Relações Étnico-Raciais (BRASIL, 2004) deseja é encorajar uma pedagogia pautada em representatividades possíveis, tanto históricas, quanto científicas. Sendo assim, acreditamos que as séries inicias do Ensino Fundamental constituem o momento ideal para o início dessa abordagem.

Para tal, precisamos assumir também, como ensina Grada Kilomba, a importância das experiências, discursos e identidades dos sujeitos que participam do processo de aprendizagem. Isso significa dizer que não basta apenas admitirmos a importância da Lei 10.639/03 no que concerne ao ensino da História e da Cultura do continente africano em todas as disciplinas, mas representa dizer que não apenas o legado do conhecimento da África estará em sala de aula, como subjetividades e vivências da população que é descendente dos povos africanos. Voltamos para Grada Kilomba, mulher negra, psicóloga, escritora, artista e teórica acadêmica, que em Memórias da Plantação (2019) nos arrebata a partir de um discurso altamente subjetivo, engajado e comprometido com sua própria narrativa:

\footnotetext{
Sendo assim, demando uma epistemologia que inclua o pessoal e o subjetivo como parte do discurso acadêmico, pois todas/os nós falamos de um tempo e lugar específicos, de uma história e uma realidade específicas - não há discursos neutros. Quando acadêmicas/os brancas/os afirmam ter um discurso neutro e objetivo, não estão reconhecendo o fato de que elas e eles também escrevem de um lugar específico que, naturalmente, não é neutro nem objetivo ou universal, mas dominante. É um lugar de poder. (KILOMBA, 2019, p. 58)
}

Apenas subvertendo a lógica desse lugar de poder, que se intitulou universal na tentativa de perpetuação dessa dominação epistêmica, como mostra a autora, teremos a Lei 10. 639/03 alcançando seu objetivo por completo. Para isso, recuperar narrativas apagadas da história única dominante se mostra força motriz e urgente, a começar pela representatividade de narrativas que são ofertadas aos nossos alunos logo que ingressam em idade escolar. Sendo assim, acreditamos e reivindicamos, como Grada Kilomba, uma educação pautada em um projeto que 
acessam o direito à educação, respeitando nossa LDBN e colocando em prática as orientações das Leis 10.639/03 e 11.645/08.

Para tal, é essencial pensarmos o papel do professor nesse processo. Voltamos a Bell Hooks, ao livro Ensinando a transgredir: a educação com prática da liberdade (2013), em que a autora desenvolve uma profunda reflexão acerca do fazer docente e do papel do professor no processo de aprendizagem. Logo na introdução, Bell Hooks, assim com Grada Kilomba, reivindica uma narrativa subjetiva, desta vez já a partir da própria escrita em primeira pessoa, revisitando suas memórias de infância, seu passado, quando aluna do Ensino Fundamental, nas linhas iniciais de seu texto. Ela nos conta como era a rotina da "escola Booker T. Washington" (HOOKS, 2013, p. 10), onde diz ter vivido uma experiência de aprendizado revolucionária. Nessa escola, frequentada somente por negros e com quase todo seu quadro de professores composto por mulheres negras, Hooks nos chama a atenção para o compromisso político assumido pelas docentes, já que o aprendizado dessa escola era fundamentalmente pensado a partir da luta antirracista:

\footnotetext{
O compromisso delas era nutrir nosso intelecto para que pudéssemos nos tornar acadêmicos, pensadores e trabalhadores do setor cultural - negros que usavam a "cabeça". Aprendemos desde cedo que nossa devoção ao estudo, à vida do intelecto, era um ato contra-hegemônico, um modo fundamental de resistir a todas as estratégias brancas de colonização racista. Embora não definissem nem formulassem essas práticas em termos teóricos, minhas professoras praticavam uma pedagogia revolucionária de resistência, uma pedagogia profundamente anticolonial (HOOKS, 2013, pp. 10-11)
}

Nas palavras da autora, percebemos que o ato revolucionário vivenciado por ela se constituiu pela prática de suas professoras das séries inicias do Ensino Fundamental, quando, mesmo em meio a um currículo centrado na história única colonizadora, subverteram essa unidade histórica, oferecendo a seus alunos uma educação que pudesse questionar as estratégias brancas de narração do mundo, assim como fortaleceram a autoestima dessas crianças através da reafirmação das narrativas pessoais como fator importante na construção da intelectualidade. Também acreditamos ser essa fase escolar de suma importância no que diz respeito a formação crítica dos nossos discentes, ainda crianças. Isso deve ser feito, principalmente, a partir de uma sala de aula que se mostra espaço de revolução, quando desafia as amarras da colonização, se fazendo resistente às práticas racistas que ainda não foram totalmente superadas por nosso currículo e material didático.

Diante disso seguem algumas reflexões: Como são representados homens nos livros de Ciências? Como são representadas mulheres nos livros de Ciências? Como são representados homens brancos e mulheres brancas nos livros de Ciências e nos conteúdos temáticos? E homens negros e mulheres negras? Estes são contemplados imageticamente nos nossos livros didáticos científicos ou em temáticas de produção epistemológica? A Lei 10.639/03 incentiva que reflexões assim sejam feitas e que seja possível descolonizar saberes, valorizando nosso legado cultural e histórico oriundo do continente africano e nossa raiz afrobrasileira.

Página | 561

Na continuidade da obra, Hooks nos conta que já no Ensino Médio isso foi bem mais desafiador, pois ela não mais tinha professores, principalmente professoras, 
negros/as em maioria. Ainda que pautados em um discurso que falasse sobre igualdade, a prática se distanciava de forma contundente do discurso desses docentes. No entanto, sua base construída ainda na infância, fez com que ela continuasse a acreditar na ação transformadora da educação, para, inclusive, perceber a necessidade de uma crítica profunda à forma como professores e professoras conduziam sua docência. Já adulta, encontra em Paulo Freire aquilo que seria sua grande inspiração para (re)pensar uma pedagogia engajada e nos confessa, a partir da subjetividade da sua experiência enquanto aluna e, depois, professora o seguinte:

\begin{abstract}
Umas das coisas que me decepcionou muito foi conhecer professores brancos, homens, que afirmavam seguir o modelo de Freire ao mesmo tempo em que suas práticas pedagógicas estavam afundadas nas estruturas de dominação, espelhando os estilos dos professores conservadores embora os temas fossem abordados de um ponto de vista mais progressista (HOOKS, 2013, pp. 30-31).
\end{abstract}

A subjetividade desta narrativa de Bell Hooks nos convida, enquanto pesquisadores preocupados com a formação de professores, a uma autocrítica em relação a nossa conduta, assim como nos traz à tona, novamente, uma possibilidade de diálogo com a Lei 10.639/03, que salienta a importância de valorizarmos as epistemologias oriundas do continente africano também por ser nossa sociedade formada principalmente por pessoas que se autodeclaram pessoas negras. Em um núcleo social assim, não podemos fechar os olhos para a importância da representatividade em nossos conteúdos e práticas pedagógicas. Ou seja, teoria e prática que se desejam libertadoras precisam andar de mãos dadas. Portanto, acreditamos que isso deve já ser assumido nas séries inicias do Ensino Fundamental e este trabalho se compromete em pensar estratégias possíveis para efetivação desta proposta. $O$ caminho escolhido é do enlace entre ciência e literatura.

Antonio Candido, crítico literário, há alguns anos, escreveu um importante ensaio intitulado "O direito à Literatura" (2011). Nesses escritos, o autor reflete acerca dos Direitos Humanos, reconhecendo, assim, tudo aquilo que seria indispensável aos sujeitos sociais. Problematiza a ideia de que muitos defendem o direito a certos bens, tais como alimentação, saúde, comida, educação, mas que não são capazes, muitas vezes, de concordar com o direto também à arte literária.

Não é que as pessoas estejam erradas quando afirmam ser fundamental comer, estudar e ter acesso ao cuidado em saúde, ressalta Candido (2011). Sim, tudo isso se configura imprescindível à garantia da vida do sujeito. No entanto, ele argumenta que não são apenas esses bens, considerados incompressíveis, aquilo que de fato totaliza a construção social desse sujeito no mundo. Moradia, vestuário, saúde pública, instrução básica são, certamente, essenciais aos homens, assim como o lazer, a crença, a liberdade e a Literatura! Não seria então a Literatura também um direito? Por que não?

Como afirma Candido, a literatura é ação poderosa na sociedade, pois é poder que humaniza enquanto (re)constrói e significa o mundo aos sujeitos sociais que somos. Afinal, a "literatura confirma e nega, propõe e denuncia, apoia e combate, fornecendo a possibilidade de vivermos dialeticamente os problemas" (CANDIDO, 2011, p. 177). Literatura é arte. Literatura é viver. Literatura é conhecimento. 
Literatura é experiência. Literatura é, portanto, um direito. Neste artigo, optamos por uma literatura engajada com outro direito e luta: um mundo antirracista.

Voltamos para Bell Hooks, salientando que essa professora, mulher negra, feminista e teórica, também é escritora. Ainda em Ensinando a transgredir (2013) relembra que o sonho de escrever sempre esteve presente em si. Ela diz que acreditava que iria lecionar e que este seria seu emprego, mas que escrever seria o seu trabalho. Escrever, ressalta Hooks, se mostrava a ela como um ato revolucionário. Justamente, por atender ao chamado da escrita que a convocava para uma forma de pensar uma prática verdadeiramente engajada e libertária, escolhemos a obra de literatura infantil, de Bell Hooks, Meu crespo é de rainha, publicada em 2018.

Nosso artigo constrói uma proposta para efetivação da Lei 10.639/03 junto ao ensino de Ciências, a partir da apresentação deste livro literário de Bell Hooks, passível de ser adotado nas séries iniciais do Ensino Fundamental. Com um título que já evoca o sujeito a narrar sua própria história, utilizando o pronome em primeira pessoa "meu", a obra se constrói a partir da pauta anticolonial já na subversão dos padrões de beleza impostos também pela cultura hegemônica, possibilitando que o professor possa ter em mãos outros recursos imagéticos para uma aula pautada também em uma vontade de fazer outra Ciência. É importante salientar que a voz silenciada, mas que emerge dessa literatura produzida por Bell Hooks, é feminina, o que não é banal, principalmente quando sabemos ser a mulher negra aquela que em nossa sociedade se depara com as piores formas de opressão possíveis: racismo, sexismo e classe. Percebemos, então, que a obra de Hooks se mostra por completo como uma proposta que pode descolonizar saberes, não apenas pelo seu enredo, como também pelo narrador feminino e pelas imagens sugeridas.

O processo de autoria de Hooks na produção dessa obra literária traz questões que emergem não só da vivência da autora como mulher negra, mas de todo o coletivo que vivencia as marcas dos padrões estéticos construídos pela modernidade colonialista em prol da continuidade do processo de subalternização dessas pessoas. Com base nisso, Cusicanqui (2015) nos chama a atenção das imagens construídas a partir do olhar das pessoas subalternizadas como esperança de uma leitura de mundo que seja comprometida com a justiça e a superação das amarras coloniais. Nesse processo de criação de imagens podemos incluir não só as representações visuais, mas também a própria palavra ressignificada dos povos marginalizados.

Por fim, retomamos as palavras de Verena Alberti ao responder a seguinte indagação: por que implementar uma lei que busca promover Educação das Relações Étnico-Raciais? Em resposta, ela afirma: "Porque a sociedade como um todo, os alunos, de diferentes raças e cores, seus pais, seus irmãos, seus amigos e seus filhos se beneficiarão se tivermos oportunidades de explorar a diversidade e desafiar o racismo" (2013, p. 55). Enfim, que esta nossa produção inicial possa, de alguma forma, contribuir para construção de um legado com base na igualdade e no respeito, tendo a educação como via fundamental sempre.

Página | 563 


\title{
A OBRA MEU CRESPO É DE RAINHA, DE BELL HOOKS, E O ENSINO DE CIÊNCIAS: DESCOLONIZANDO SABERES A PARTIR DA LITERATURA INFANTIL
}

A autora Bell Hooks em seu livro infantil Meu crespo é de rainha explora recursos para além da subversão da palavra quando reafirma em seu título que seu cabelo é de rainha. Contrapondo-se aos padrões estéticos estabelecidos pela lógica eurocêntrica dominante, Bell Hooks nos convida a pensar sobre o cabelo de forma não só política - através da afirmação da autoestima - como também nos possibilita olhar para a ancestralidade, pois, ao pensarmos em cabelo crespo de rainha, impossível não lembrarmos das grandes rainhas africanas e suas relações com o cabelo como símbolo de poder e pertencimento. Esse tipo de movimento de ressignificação através da literatura é de suma importância visto que o cabelo crespo, desde os tempos remotos da colonização, têm sido alvo de constantes ataques, como afirma a autora Nilma Lino Gomes:

\footnotetext{
No regime escravista, a "lida" do escravo implicava trabalhos forçados no eito, na casa-grande, na mineração. Implicava também, a violência e os açoites impingidos sobre o corpo negro. Entre as muitas formas de violência impostos ao escravo e à escrava estava a raspagem do cabelo. Para o africano escravizado esse ato tinha significado singular. Ele correspondia a mutilação, uma vez que o cabelo, para muitas etnias africanas era considerado uma marca de identidade e dignidade (GOMES, 2017, pp. 21-22)
}

A desvalorização histórica do cabelo crespo é refletida, inclusive, no próprio ambiente escolar em que crianças negras são alvo de episódios racistas, como lembra a autora e filósofa Djamila Ribeiro, em sua obra Quem tem medo do feminismo negro? (2018). Djamila, ao relembrar parte da sua infância, menciona o fato de que

\begin{abstract}
todo dia eu tinha que ouvir piadas envolvendo meu cabelo e a cor da minha pele. Lembro que nas aulas de história sentia a orelha queimar com aquela narrativa que reduzia os negros à escravidão, como se não tivessem um passado na África, como se não houvesse existido resistência. Quando aparecia a figura de uma mulher escravizada na cartilha ou no livro, sabia que viriam comentários como "olha a mãe da Djamila aí". Eu odiava essas aulas ou qualquer menção ao passado escravocrata - me encolhia na carteira tentando me esconder (RIBEIRO, 2018, pp. 7-8).
\end{abstract}

Diante desse cenário, mais uma vez, reforçamos a importância da escola no compromisso da efetivação da Lei 10.639/03 e da necessidade do acesso a obras literárias que permitem que questões acerca da comunidade negra possam ser consideradas na prática pedagógica, inclusive, no ensino de Ciências.

Nilma Lino Gomes (2003), ao exemplificar a importância de se tratar a cultura negra no nosso país, também afirma que a questão educativa, de modo geral, é eminentemente cultural, ou seja, uma cultura que é intrínseca em toda a sociedade brasileira. Assim, a relação ensino/aprendizagem se estrutura no campo dos valores, de diferentes lógicas, de representação e não apenas através de processos cognitivos. Para o homem, mulher ou criança negra, manipular o cabelo significa a representação de uma das muitas expressões da corporeidade e da cultura, remetendo a uma raiz ancestral.

Página | 564

Dessa forma, a reivindicação da valorização do cabelo e do corpo negro, em diálogo com a cultura e história africana e afro-brasileira, na nossa sociedade, foi/é 
um importante passo para se pensar em práticas pedagógicas verdadeiramente emancipatórias, principalmente, no que diz respeito à descolonização dos currículos das escolas do Brasil. Como aponta novamente Nilma Lino Gomes (2012), a obrigatoriedade do ensino de História da África e das Culturas afrobrasileiras nas escolas possibilitou que novas estratégias pedagógicas pudessem emergir, inclusive, em diálogo com a arte. Dentro dessa perspectiva, torna-se possível viabilizar os diversos aspectos socioculturais que acabam, na maioria das vezes, sendo negligenciados pelos currículos atuais.

Sendo assim, a escolha pela literatura infantil de Bell Hooks como possibilidade para a educação em Ciências nas séries iniciais se apresenta como horizonte possível devido às características intrínsecas presentes no livro. Nele, podemos observar não só o resgate da ancestralidade africana através da diversidade e valorização de formas de penteados de cabelo e cores apresentadas pelas ilustrações presentes, mas também a reivindicação do cabelo crespo como parte do corpo humano e que possui grande importância histórica, social e biológica a partir da perspectiva de pessoas negras. Ao afirmar que o cabelo crespo se trata de outra forma de representação de cabelo humano, podemos nos voltar para a diversidade como fator importante da manutenção da vida.

No livro de Bell Hooks, as múltiplas representações de cabelo crespo, assim como diferentes tonalidades da pele negra, nos remetem à ideia de que, apesar das diferenças encontradas entre os tipos de cabelos e de cor, todos eles são importantes, pois apresentam suas próprias características biológicas que conferem diferentes texturas, tonalidades, medidas e conformações assim como as demais partes do nosso corpo. Quando apontamos nas aulas de Ciências a pluralidade existente entre nós seres humanos, rompemos com ideias universalistas que impõem padrões excludentes acerca do conceito de corpo humano e que são excludentes também para a maioria da população brasileira que não se enquadra no estereótipo branco e europeu. Essa maioria também está em nossa sala de aula. A espécie humana é diversa e desempenha papel importante na manutenção do meio ambiente e das relações sociais. Para acessar esse tipo de discussão, a escolha de imagens representativas faz toda a diferença para o estabelecimento de novas conexões cognitivas e emocionais dentro do processo formativo das crianças das séries iniciais.

A leitura imagética a partir da obra produzida por uma mulher negra representa um exercício prático de descolonização de saberes, pois, através da literatura e das ilustrações, novas imagens são formadas no imaginário de todos nós. A compreensão científica pautada nas experiências de vida de pessoas subalternizadas reconstrói outros enredos e mundos, amplia conceitos científicos pré-estabelecidos e constrói novos paradigmas. Nesse sentido, para a autora Silvia Cusicanqui, a identificação dos indivíduos a partir de imagens geradas pelos subalternizados, constitui fator relevante para o sentimento de pertencimento que fora minado através das políticas colonialistas. Portanto, para a autora as imagens oferecem interpretações e narrativas sociais capazes de nos provocar para outras perspectivas de compreensão crítica da realidade. Para exemplificar, trazemos a imagem da capa do livro, para que, a partir dela, a potencialidade do trabalho com tal narrativa que faz emergir da literatura imagens e mundos outros seja vislumbrada: 
Figura 1 - Capa do livro Meu crespo é de rainha

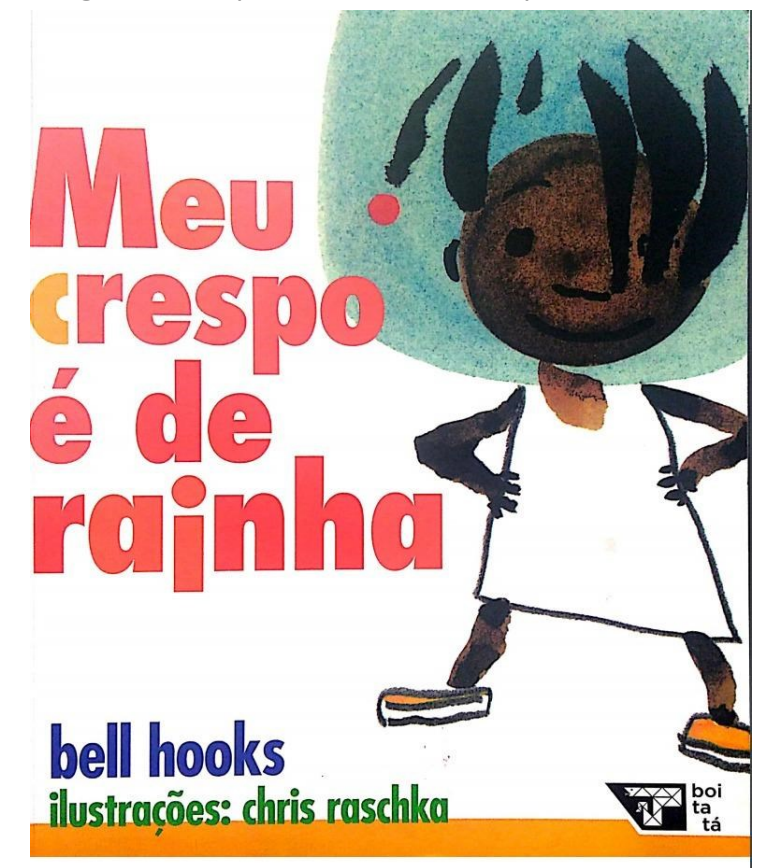

Fonte: HOOKS (2018).

Considerar o diálogo da literatura com o ensino de Ciências pode nos proporcionar experiências relevantes no exercício da Lei 10.639/03 nas séries iniciais do Ensino Fundamental. Portanto, a literatura - como direito humano e fundamental a todas as pessoas - não se limita apenas como recurso pedagógico, mas sim, como uma forma de descolonização dos saberes a partir de sua capacidade de construir novos cenários de possibilidades. Ao observamos a capa do livro, por exemplo, somos arrebatados pelas cores que transmitem alegria antes mesmo da leitura das palavras. A representação humana através da ilustração da criança negra expressando felicidade e alegando que seu crespo é de rainha não trata apenas de uma afirmação, mas tem como intuito também realizar um convite para que possamos descolonizar o espaço escolar a partir da nossa prática cotidiana, inclusive, nas aulas de Ciências. Isso significa pensar que a aposta pela literatura na educação em Ciências para, além da efetivação da lei, promove não só o exercício da justiça, como também a formação de sujeitos pensantes, portanto, como nos lembra Cusicanqui (2015, p. 307, tradução nossa): “Nossa posição como sujeitos pensantes esta marcada pela nossa própria história, pela geografia de nossas colinas e por nossa própria genealogia intectual. [...] temos outros horizontes de esperança, e é isso que nos distingue".

\section{CONSIDERAÇÕES FINAIS: PERCURSOS AINDA EM (RE)CONSTRUÇÃO}

Nestas reflexões finais, evocamos a coragem inerente a todo educador, exaltada por Freire em Educação como prática da Liberdade (2007, p. 104): “A educação é um ato de amor, por isso, um ato de coragem. Não pode temer o debate. A análise da realidade. Não pode fugir à discussão criadora, sob a pena de ser uma farsa". Freire nos convoca a desafiar sistemas opressores e isso se faz também no fazer docente cotidiano, nas outras possibilidades do professor construir recursos, materiais, aulas que não se limitem a reproduzir a história única 
colonizadora, assim, como viabilizar que diálogos entre conhecimentos sejam reconhecidos também como pertinentes a uma educação que se deseja plural já nas séries inicias do Ensino Fundamental.

Neste artigo, buscamos mostrar laços entre ciência, descolonização do conhecimento e literatura na tentativa de encaminhar uma proposta que já nas séries iniciais do Ensino Fundamental se comprometa com uma formação cidadã justa e verdadeiramente igualitária. Pensamos que, para isso, caminhos devem ser traçados e atividades devem ser pensadas como ferramentas que tornarão a Lei 10.639/03 efetiva e significativa, já que essa legislação preza pela descolonização dos saberes. Para tal, por entre percursos teóricos, trouxemos reflexões importantes de mulheres que produzem epistemologias fundamentais para o campo teórico da descolonização. Grada Kilomba, por colocar em questão aqueles que estão a validar o que é intitulado por conhecimento, Silvia Cusicanqui por nos mostrar possibilidades outras de análise, trazendo a questão imagética como um caminho para metodologias outras e Bell Hooks, por, assim como Paulo Freire, nos levar a pensar acerca de nossa prática docente, sempre em nome de uma educação libertadora. A literatura nesse contexto, foi o enlace perfeito, a linguagem que fez emergir palavras e imagens na contribuição para um ensino de Ciências que se deseja descolonizador.

Finalizamos com o seguinte ensinamento de Paulo Freire a ser (re)assumido por todos os educadores: "a ideia da liberdade só adquire plena significação quando comunga com a luta concreta dos homens por libertar-se" $(2007$, p. 17). Dessa forma, acreditamos que esse processo libertador é percurso sempre em (re)construção e só se concebe plenamente pelo processo educacional formador do sujeito autônomo, consciente de suas subjetividades, o que deve ser incentivado desde as séries iniciais da escola, assim como deve dialogar com outras formas de leitura de mundo. Portanto, também acreditamos ser possível uma verdadeira descolonização do conhecimento científico: capaz de colaborar na formação de um legado social plural e justo em suas oportunidades. 


\title{
Possible decolonial paths in the teaching of sciences of the initial series: a dialogue with the work "meu crespo é de rainha"
}

\begin{abstract}
Our study aims to think the Science class for the early grades of elementary school from the perspective guided by the law 10.639/03, in which aspects of African History and Culture and Afro-Brazilians should be covered in every school curriculum. To this end, we bring to the fore the theoretical weaving by Silvia Cusicanqui, Grada Kilomba, and Bell Hooks, authors who problematize the decolonization of the knowledge, i.e., they propose a possibility of producing knowledge from silenced epistemologies, subjectivity, and teaching practice. Faced with what these thinkers teach us, we seek, therefore, to develop a theoretical reflection on the dialogue between law 10.639/03, the teaching of Sciences and the literature. To this end, the children's book chosen for our approach is the work Meu Crespo é de Rainha, by the black author and intellectual Bell Hooks, aiming at the alignment between our theoretical construction, literature and the scientific discipline for the early grades of elementary school. As a result, we suggest ways actualizing the law $10.639 / 03$ in a decolonial perspective, thus making the education of the ethnic-racial relations also possible to the scientific field, which can and should contribute to this discussion. We believe, therefore, that subverting the logic of a unique history based on a predominantly hegemonic scientific production is to be able to build pathways to a new science.
\end{abstract}

KEYWORDS: Science Education. Decolonization. Literature. 


\section{AGRADECIMENTOS}

Agradecemos pelo incentivo da PR-5, da UFRJ, por incentivar bolsas de extensão universitária, tornando, assim, os projetos "Afric(a)ção" e "Vou para o Sul saltar o cercado: narrativas femininas para o incentivo de meninas nas ciências", ambos da UFRJ Macaé, possíveis a nossas alunas e alunos de graduação, assim como possíveis de atuação nas escolas públicas parceiras da região. Agradecemos também pelo incentivo da CAPES, por bolsa de mestrado ao aluno de PósGraduação coautor deste texto.

\section{REFERÊNCIAS}

ALBERTI, V. "Algumas estratégias para o ensino de história e cultura afrobrasileira". In: PEREIRA, A. A.; MONTEIRO, A. M. (Orgs.). Ensino de História e Culturas afro-brasileiras e indígenas. Rio de janeiro: PALLAS, 2013.

BRASIL. Lei 9.394/1996, de 20 de dezembro de 1996. Diário Oficial da União, de dezembro de 1996.

BRASIL. Lei 10.639/2003, de 9 de janeiro de 2003. Diário Oficial da União, de janeiro de 2003.

BRASIL. Lei 11.645/2008, de 10 de março de 2008. Diário Oficial da União, de março de 2008.

BRASIL. Ministério da Educação. Conselho Nacional de Educação. Diretrizes Curriculares Nacionais para a Educação das Relações Étnico- Raciais e para o Ensino de História e Cultura Afro-Brasileira e Africana. Relatora: Petronilha Beatriz Gonçalves. Ministério da Educação. Brasília, 2004.

CANDIDO, A. Vários escritos. Rio de Janeiro: Ouro sobre Azul, 2011.

COSTA, F. A. G.; GOULART, A. L. B.; NASCIMENTO, B. I. S.; ALMEIDA, S. "Narrativas femininas para uma educação decolonial". In: MONTEIRO, B. A. P.; DUTRA, D. S. A.; CASSIANI, S. SÁNCHEZ, C; OLIVEIRA, R. D. V. L. (Orgs.). Decolonialidades na Educação em Ciências. São Paulo: Editora Livraria da Física, 2019.

CUSICANQUI, S. R. Ch'ixinakax utxiwa: Una reflexión sobre prácticas y discursos descolonizadores. Buenos Aires: Tinta Limón, 2010.

Página | 569

CUSICANQUI, S. R. Sociología de la imagen: ensayos. Buenos Aires: Tinta Limón, 2015. 
FREIRE, P. A importância do ato de ler: em três artigos que se completam. 48. ed. São Paulo: Cortez, 2.006.

FREIRE, P. Educação como prática da liberdade. 30. ed. Rio de Janeiro: Paz e Terra, 2007.

FREIRE, P. Pedagogia da autonomia: saberes necessários à prática educativa. 44. ed. Rio de Janeiro: Paz e Terra, 2013.

FURMAN, M. $\mathbf{O}$ ensino de ciências no Ensino Fundamental: colocando as pedras fundacionais do pensamento científico. São Paulo: Sangari Brasil, 2009

GOMES, N. L. Cultura Negra e Educação. Revista Brasileira de Educação. n. 23. pp. 75-84, maio / ago. 2003.

GOMES, N. L. Sem perder a raíz: corpo e cabelo como símbolos da identidade negra. São Paulo: Autêntica, 2017.

GOMES, N.L. Relações Étnico-raciais, educação e descolonização dos currículos. Currículo sem Fronteiras. v. 12, n. 1, p. 98-109, jan/abr. 2012.

HOOKS, B. Ensinando a transgredir: a educação como prática da liberdade. São Paulo: Editora WMF Martins Fontes, 2013.

HOOKS, B. Meu crespo é de rainha. São Paulo: Boitatá, 2018.

KILOMBA, G. Memórias da Plantação - Episódios de Racismo Cotidiano. Rio de Janeiro. Editora de Livros Cobogó, 2019.

PINHEIRO, B. C. S.; ROSA, K. (Orgs.). Descolonizando saberes: a Lei 10.639/03 no ensino de ciências. São Paulo: Editora Livraria da Física, 2018.

PINHEIRO, B. Educação em Ciências na Escola Democrática e as Relações ÉtnicoRaciais. Revista Brasileira De Pesquisa Em Educação Em Ciências, v. 19, p. 329344, ago. 2019.

RIBEIRO, D. Quem tem medo do feminismo negro? São Paulo: Companhia das Letras, 2018. 
Recebido: 15 ago. 2019

Aprovado: 21 out. 2019

DOI: 10.3895/actio.v4n3.10532

Como citar:

CARVALHO, I. V. de; NASCIMENTO, B. I. S. do; ALMEIDA, S.; COSTA, F. A. G. da. Caminhos descoloniais possíveis no ensino de ciências das séries iniciais: um diálogo com a obra "meu crespo é de rainha". ACTIO, Curitiba, v. 4, n. 3, p. 553-571, set./dez. 2019. Disponível em: https://periodicos.utfpr.edu.br/actio. Acesso em: $\mathrm{XXX}$

Correspondência:

lago Vilaça de Carvalho

Rua Aluízio da Silva Gomes, n. 50, Novo Cavaleiros, Macaé, RJ, Brasil.

Direito autoral: Este artigo está licenciado sob os termos da Licença Creative Commons-Atribuição 4.0

Internacional.

\section{(c) (1)}

Página | 571 